Research Article

\title{
Resource Configuration Efficiency and Influencing Factors of Elderly Care Services Based on a Data-Driven DEA-Tobit Approach
}

\author{
Dongqing Luan (D), Ziqing Zhao, and Yanxi Xie (iD) \\ School of Management, Shanghai University of Engineering Science, Shanghai 201620, China \\ Correspondence should be addressed to Dongqing Luan; shluan@163.com
}

Received 30 October 2021; Revised 19 November 2021; Accepted 26 November 2021; Published 11 December 2021

Academic Editor: Shaojian Qu

Copyright (c) 2021 Dongqing Luan et al. This is an open access article distributed under the Creative Commons Attribution License, which permits unrestricted use, distribution, and reproduction in any medium, provided the original work is properly cited.

\begin{abstract}
Efficient resource configuration is critical to providing sustainable aged care services. Empirical studies are conducted with a twostage data-driven method of DEA-Tobit. First, the BCC model of data envelopment analysis is employed, to determine whether the values obtained from the three efficiency aspects (namely technical, pure technical, and scale) are situated in the frontiers of production, whether DEA is effective, and whether the problems of uneconomical scale or low technical level are available. Next, the causes of these problems are analyzed. Then, the regression analysis is performed using Tobit with the influencing factors including GDP, the number of institutions engaged in elderly care, the number of day service centers in the communities, the number of medical service institutions for the elderly, and the density of the elderly population. Known as a city with a severely aging population, Shanghai will be selected for a case study to propose countermeasures from the three dimensions of the elderly group, the elderly care industry, and the market environment.
\end{abstract}

\section{Introduction}

Global aging has a large and profound impact on society's long-term growth [1]. In the coming twenty years, the number of elderly people will undoubtedly rise in China [2]. Because of falling birth rates and rapidly growing life expectancy, rapid aging, which has serious economic consequences, has become a critical issue in China. As the population of the elderly grows, so will the demand for health services and aged care [3]. Against the background of active aging, the continuous improvement of the security and quality of the livelihoods of elderly people is not only an urgent requirement for continuous economic development and the further promotion of social civilization but also the accelerated promotion of economic and social stability.

Accordingly, properly configuring the resources required to provide senior care services would be a critical issue. There are several articles on this subject in the literature. Reference [4] conducted an efficiency analysis of the elderly care sector in Norway, revealing substantial variation in efficiency. Inefficient configuration of elderly resources may result in various issues besides increased costs. Reference [5] considered the correlation of clinical quality and productive efficiency in institutional long-term elderly care. Reference [6] presented the inequalities of elderly population in Germany based on morbidity-related and socioeconomic inequalities and the resulting financial burden.

From another perspective, understanding the determinants of resource configuration efficiency of elderly care service is essential to illuminate the potential improvement for better efficiency. The researchers used various methods from different perspectives to investigate the problem. For example, [7] adopted logistic regression to explore potential determinants in using those services. Reference [8] investigated quality of care and efficiency in nursing homes through DEA with an Italian example. Reference [9] explored decisive factors of long-term care and compared features of the community/home-based and of institutionbased service users. Reference [10] provided a three-stage data envelopment analysis to investigate the efficiency of provincial social elderly care among 148 Councils in Britain. Reference [11] proposed an evaluation method with 33 
indicators and compared the performance of communitybased elderly care service centers with that of home-based ones in six dimensions.

As is the growing trend in elderly care, there is a significant waste of elderly care resources due to the lack of highly efficient management. Efficient resource configuration is an essential goal and needs to be evaluated well. Reference [12] introduced and performed the second-stage DEA efficiency analysis in the generating process of censoring data, with an empirical study to evaluate the configuration efficiency and explore the impacting factors. Reference [13] mentioned that Tobit regression is often encountered in second-stage DEA and concluded that the Tobit approach will in most cases be sufficient in representing second-stage DEA models. A similar approach has been taken in other areas, such as energy or medical services [14-16]. Reference [17] proposed a two-stage DEA model for efficiency assessments of wind powers. Reference [18] aimed to evaluate the technical efficiency of public and private hospitals in Beijing, China, and analyze the influencing factors of hospitals' technical efficiency.

The rest of the paper is constructed as follows. Section 2 discusses the theories of DEA analysis. Section 3 provides DEA results using Shanghai as an example. The results of the efficiency determinants are presented in Section 4. Concluding remarks are given in Section 5.

\section{DEA Formulation and Preliminaries}

2.1. Adoption of DEA Model. Data envelopment analysis (DEA) provides an insight to evaluate the relative efficiency demonstrated by a set of decision-makers with sufficient inputs and outputs.

There are two fundamental models: the CCR model, which is proposed by Charnes, Cooper, and Rhodes in 1978 and the BCC model proposed by Bankers, Charnes, and Cooper in 1984 [19-21]. The difference between the two models lies in the fact that the CCR model has the premise of constant return to scale (CRS), while the BCC model has the premise of variable return to scale (VRS). Thus, the former can only be used to evaluate the decision-making units (DMUs) with constant returns to scale. This model can only compute technical efficiency value, instead of being decomposed to scale and pure technical efficiency value and directly evaluating the effectiveness of DUM. By adding a constraint to the CCR model, the BBC model ameliorates the problems noted above. The technical efficiency value can therefore be broken down into a pure technical efficiency value and a scale efficiency value, the formula CRSTE $=$ VRSTE $*$ SCALE being fulfilled.

In the study on the evaluation model of input-output efficiency, the input-oriented BBC model is mainly adopted to evaluate the efficiency of the resource configuration. In other words, the input is reduced as much as possible under the condition of a fixed output. First, the resource configuration of the elderly care services is subjected to not only the influence imposed by the external environment (such as related policies and the mechanism of market competition) but also some internal environments. Hence, the guidance over the input of elements under the fixed output is explored in this study to decrease the factors. On this basis, the inputoriented type is selected. Furthermore, in comparison with the BCC model, the CCR model can only be employed to calculate the technical efficiency value of the resource configuration of the elderly care services. It is unable to decompose pure technical efficiency value and scale efficiency value. On the other hand, the BCC model works for technical efficiency value, pure technical efficiency, and scale efficiency. Therefore, the BBC model is more conducive to comprehensively analyzing the key issues surrounding the resource configuration of the elderly care services.

2.2. The Inputs and Outputs of DEA Model. To simplify, when defining the resource configuration of the elderly care services, the input of the resource associated with the aged care services is divided by the output. From another perspective, it can be understood as a comparison of the technical efficiency values obtained from the resource configuration of the elderly care services to determine which is larger.

From an input perspective, there are different types of resources available to aged care services. According to the principle in the selection of indexes and the availability to the statistics, the pension from the retired personnel is first selected because it is the main financial source of the aged. Additionally, a large amount of literature review demonstrated that the indexes frequently used to evaluate the resource configuration of the elderly care services contain the number of the institutions engaged, the number of senior care beds, the number of institutions possessed by every one thousand seniors, and the number of beds possessed by every one thousand seniors. According to the evaluation indexes of elderly care services conducted in institutions and communities and the accessibility of the statistics data, institution-based elderly care services and the number of daycare institutions caring for the elderly in communities are taken as the indexes.

From an output perspective, the paper adopts the number of yearly served seniors and the population of the seniors over 60 years old as the output indexes for the evaluation over the resource configuration of the elderly care services. It is revealed that it conforms to the requirement for the correlation between input indexes and output of the DEA model and can comprehensively reflect the connection between the resource configuration efficiency and the growth rate of the elderly.

2.3. Data Source. Shanghai is already one of the cities with the highest degree of aging in China. The steadily growing population of the aged has presented great demand for economic supply, medical care, basic daily care, and spiritual relief. A typical meaning can be demonstrated in the research on the resource configuration of the elderly care services in Shanghai.

The statistics of the study come from the Shanghai Statistical Yearbook and the Shanghai Municipality's Elderly Population and Elderly Career Monitoring Statistics from 
2010 to 2019. This ensures that the statistics are meaningful to a certain extent. Given the accessibility of statistics, the resource about the elderly care services in Shanghai is selected as the evaluation sample in this paper to compare and analyze the efficiency of the resource configuration in different years, as shown in Table 1.

Given that there are differences in the dimension of different indexes, the treatment of nondimensionalization is conducted for different indexes and statistics before the analysis on DEA to ensure the results obtained from the analysis. The formulas are

$$
\begin{array}{ll}
x_{i j}^{\prime}=0.1+\frac{x_{i j}-\min _{j}}{\max _{j}-\min _{j}} \times 0.9, & 0.1 \leq x_{i j}^{\prime} \leq 1, \\
y_{i j}^{\prime}=0.1+\frac{y_{i j}-\min _{j}}{\max _{j}-\min _{j}} \times 0.9, & 0.1 \leq y_{i j}^{\prime} \leq 1,
\end{array}
$$

where $x_{i j}$ indicates various original data of the inputs; $y_{i j}$ denotes the original data of the outputs; $\min _{j}$ represents the minimum value in the statistics of indexes; and $\max _{j}$ denotes the maximum value in the index statistics. The statistics after the treatment of nondimensionalization offset the influence imposed by dimension. The range of values is $0.1 \leq x \leq 1$, as shown in Table 2.

\section{The Results of the DEA Analysis}

With the software of DEAP2.1, a DEA calculation for the resource configuration efficiency of the elderly care services in Shanghai from 2010 to 2019 is carried out in this study. Under the condition of variable scales, CRSTE, VRSTE, and Scale are obtained from the resource configuration of the elderly care services in Shanghai, including the scale effect from 2010 to 2019.

In the DEA analysis, IRS and DRS indicate ascending returns to scale and descending returns to scale, respectively; "-" denotes constant returns to scale. In addition, CRSTE, VRSTE, and SCALE represent technical efficiency, pure technical efficiency, and scale efficiency, respectively. Technical efficiency is equal to pure technical efficiency multiplied by scale efficiency. The final efficiency results are shown in Table 3.

Regarding the resource configuration of the elderly care services in Shanghai from 2010 to 2019, the graphic of changes for technical efficiency, pure technical efficiency, and scale efficiency of input-output are depicted using Excel. The horizontal axis and the vertical axis indicate years and the efficiency values obtained from DEA computation in different years, respectively. The line chart reflects the changes in the technical efficiency, pure technical efficiency, and scale efficiency, as illustrated in Figure 1.

3.1. Technical Efficiency. Technical efficiency refers to the production efficiency generated by input factors, under the prerequisite of a comprehensive measurement and evaluation of the resource configuration capability and resource usage for DUM. According to the DEA calculation, the average technical efficiency score from 2010 to 2019 is 0.864 , which suggests that the resource of the elderly care services in Shanghai plays a role of $86.4 \%$. From the previous part, it can be seen that if the value of technical efficiency in a certain year is 1 , the efficiency of the resource of the elderly care services in that year reaches production limit. This demonstrates that the resource configuration of the elderly care services reaches the level is relatively effective.

Figure 1 indicates that the technical efficiency reached 1 in 2014, while both pure technical efficiency and scale efficiency reached 1 , realizing the relative efficiency of DEA. The variation trend of technical efficiency can be divided into three stages. (1) The stage of increasing from 0.757 to 0.990 from 2010 to 2012 demonstrates that resource configuration in Shanghai during this period. (2) The stage of fluctuation from 2012 to 2014 (first decreasing and then increasing to the efficiency value of 1 , then holding it constant) shows that the situation of wasting resources can exist, and the effective value was realized in 2014 through constant structural adjustment. (3) The stage of decreasing has appeared since 2014. The rule exhibited by efficiency value is gradually decreasing, and the efficiency value of 1 drops to 0.757 . In combination with the status quo analysis of the resource configuration of the elderly care services in Shanghai, it can be revealed that a conflict in the resource configuration or the waste of resources after 2014 can be identified.

3.2. Pure Technical Efficiency. Pure technical efficiency denotes the efficiency brought to DMU by reforming systems and management levels within the framework of the input scale of a specific resource. It reflects the management level in the resource configuration of the elderly care services in Shanghai. If the pure technical efficiency is equivalent to 1 , the resource configuration utilization rate is currently effective based on the current systems and management level.

The analysis results show that the average value obtained from pure technical efficiency of resource configuration of the elderly care services in Shanghai reached 0.990 from 2010 to 2019. With the exception of 2011, 2015, and 2016, the effective purely technical efficiency was achieved with a share of $70 \%$. According to the general level of the years examined, the pure technical efficiency of resource configuration of the elderly care services in Shanghai was relatively high, suggesting a high level of system and management level. Therefore, the resources input can be effectively used at the current level of technical management.

3.3. Scale Efficiency. According to the DEA calculation, scale efficiency reflects the difference between actual scale and optimal scale of the present resource configuration of the elderly care services under the premise of the system and management at a certain level. When the scale efficiency of DMU is equivalent to 1 , the resource has achieved the optimal scaling configuration.

From 2010 to 2019, the average scale efficiency of resource configuration of the elderly care services in Shanghai was 0.872 and thus remained a relatively excellent state. The change of scale efficiency was almost the same as that of technical efficiency, implying that the influence of pure 
TABLE 1: Evaluation index of the efficiency of pension resources allocation.

\begin{tabular}{cccc}
\hline Year & $\begin{array}{c}\text { Input index } \\
X_{1} \text { : pension for retired personnel } \\
(100 \text { million yuan })\end{array}$ & $\begin{array}{c}\text { Output index } \\
X_{2} \text { number of pension resource institutions per 1,000 } \\
\text { elderly people (number) }\end{array}$ & $\begin{array}{c}Y_{1} \text { : population receiving annual service } \\
(10,000 \text { persons })\end{array}$ \\
\hline 2010 & 783.42 & 0.369 & 331.02 \\
2011 & 912.71 & 0.360 & 347.76 \\
2012 & 1018.79 & 0.341 & 367.32 \\
2013 & 1192.33 & 0.330 & 387.62 \\
2014 & 1377.17 & 0.328 & 413.98 \\
2015 & 1658.44 & 0.335 & 435.95 \\
2016 & 1957.76 & 0.331 & 457.79 \\
2017 & 2265.11 & 0.330 & 483.60 \\
2018 & 2469.00 & 0.334 & 503.28 \\
2019 & 2690.27 & 0.345 & 518.12 \\
\hline
\end{tabular}

TABLE 2: Input-output data for dimensionless process.

\begin{tabular}{cccc}
\hline Year & Pension for the retired & $\begin{array}{c}\text { Number of institutions possessing pension resource per } \\
\text { thousand elders }\end{array}$ & $\begin{array}{c}\text { Population of the elderly receiving service } \\
\text { annually }\end{array}$ \\
\hline 2010 & 0.100 & 0.916 & 0.100 \\
2011 & 0.161 & 0.775 & 0.181 \\
2012 & 0.211 & 0.269 & 0.276 \\
2013 & 0.293 & 0.100 & 0.375 \\
2014 & 0.380 & 0.100 & 0.502 \\
2015 & 0.513 & 0.409 & 0.609 \\
2016 & 0.654 & 0.353 & 0.715 \\
2017 & 0.799 & 0.438 & 0.840 \\
2018 & 0.896 & 0.663 & 0.936 \\
2019 & 0.100 & 0.100 & 0.100 \\
\hline
\end{tabular}

TABLE 3: Efficiency results of Shanghai pension service.

\begin{tabular}{lcccc}
\hline Year & CRSTE & VRSTE & SCALE & Returns to scale \\
\hline 2010 & 0.757 & 1.000 & 0.757 & irs \\
2011 & 0.851 & 0.938 & 0.907 & irs \\
2012 & 0.990 & 1.000 & 0.990 & irs \\
2013 & 0.969 & 1.000 & 0.969 & irs \\
2014 & 1.000 & 1.000 & 1.000 & - \\
2015 & 0.899 & 0.989 & 0.909 & drs \\
2016 & 0.828 & 0.977 & 0.847 & drs \\
2017 & 0.796 & 1.000 & 0.796 & drs \\
2018 & 0.791 & 1.000 & 0.791 & drs \\
2019 & 0.757 & 1.000 & 0.757 & irs \\
mean & 0.864 & 0.990 & 0.872 & \\
\hline
\end{tabular}

technical efficiency on technical efficiency was small due to a high level of pure technical efficiency approaching 1 . Hence, the scale efficiency is the key factor for the technical efficiency of resource configuration of the elderly care services in Shanghai.

The total change in returns to scale can be broken down into three stages as follows. First of all, the stage of increasing returns to scale from 2010 to 2013 suggests that the input of resource and the scale of resource configuration should be enlarged during this period. Second, the stage of constant

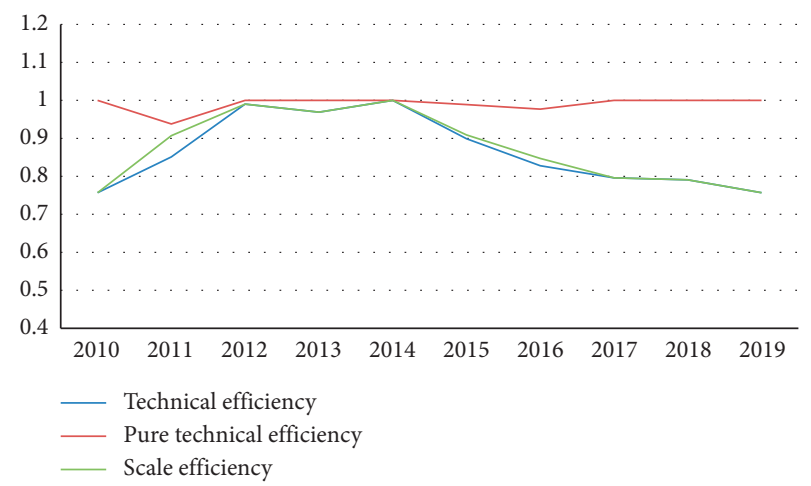

FIgURE 1: Line graph of technical efficiency, pure technical efficiency, and scale efficiency.

return to scale was only achieved in 2014. Third, the stage of decreasing returns to scale from 2015 to 2018 indicates that the input was unable to obtain the output of the same level, and the input structure about the resource configuration of the elderly care services in Shanghai was not reasonable. In addition, there was a trend towards economies of scale up to 2019, which shows that the configuration of the resources for elderly care in Shanghai has been continuously optimized and further developed. 


\section{Explaining Variations in Efficiency with Tobit}

In the previous sections, the input-output efficiency of the resource configuration of the elderly care services in Shanghai was measured. The analysis results verified that effective and invalid DEA are available in different years. However, the introduction of the Tobit model facilitates the measurement of the efficiency value obtained from DMU with the DEA model to examine the factors influencing the resource configuration efficiency of various other care services for elderly in Shanghai.

The resource configuration of elderly care services is the result caused by the role played by many parties together, mainly including input, output, and social environment. Regarding the social environment, the factors influencing resource configuration of elderly care services exhibit characteristics of diversity and complexity. Other researchers suggested that it is majorly composed of economic level, industry level, and social environment.

4.1. Introduction of Tobit. The Tobit model was proposed by Tobin in 1958 [22]. It is a model with a limited dependent variable. Since the value range of the efficiency value through DEA computation is $[0,1]$, derivation will exist in the result during the estimation if the least square method is adopted. However, in the finite dependent model, the expected error is not zero. The maximum likelihood method, the Tobit model, is therefore used for the calculation in order to effectively avoid the above-mentioned derivation [23]. It can be further illustrated using a formula.

The maximum likelihood method is applied to parameter estimation of the Tobit model. The maximum likelihood function is expressed as follows:

$$
L=\prod_{y_{i}=0}\left(1-F_{i}\right) \prod_{y_{i}>0}-\frac{1}{\sqrt{2 \pi}} \exp \left[-\frac{1}{2 \sigma^{2}}\left(y_{i}-\beta x_{i}\right)^{2}\right], \quad F_{i}=\int_{-\infty}^{\beta_{x} / \sigma} \frac{1}{\sqrt{2 \pi}} \exp \left[-\frac{t^{2}}{2}\right] \mathrm{d} t
$$

In the above formula, the first part represents the product obtained from the probability of the effective DMU; the second part expresses the product obtained from the probability of the ineffective DMU. Fi denotes the standard normal distribution on the interval. In this paper, the value range of the resource configuration of the elderly care services is $[0,1]$, and the analysis using Tobit regression is reasonable. The Tobit model can deliver relatively concrete results to the degree of influence imposed by different influencing factors on efficiency. In addition, derivation and inconsistency in the results are not available. The Tobit regression analysis is better suited to the limited dependent variable situation. Thus, the Tobit model in this study is finally written as follows:

$$
\begin{aligned}
& Y_{i}^{*}=\beta_{0}+\beta_{i} X_{i}+\varepsilon_{i}, \\
& Y_{i}= \begin{cases}0, & \beta_{0}+\beta_{i} X_{i}+\varepsilon_{i} \in(-\infty, 0], \\
Y_{i}^{*}, & \beta_{0}+\beta_{i} X_{i}+\varepsilon_{i} \in(0,1], \\
1, & \beta_{0}+\beta_{i} X_{i}+\varepsilon_{i} \in(1,+\infty],\end{cases}
\end{aligned}
$$

where $\varepsilon_{i} \sim N\left(0 \sigma^{2}\right) ; Y_{i}^{*}$ presents the potential vector quantity of dependent variable; $Y_{i}$ denotes the vector quantity of limited dependent variable; $X_{i}$ indicates the vector quantity of variable vector, that is, the influencing factors of efficiency; $\beta_{0}, \beta_{i}$ and $\varepsilon_{i}$ designate the constant term, the vector quantity of regression coefficient, and the random error term, respectively.

4.2. Determinants Analysis of Resource Configuration. The reasons for the micro factors influencing the resource configuration efficiency of the elderly care services in Shanghai are complicated. It is difficult to obtain all the relevant information. In this paper, the influence of macro factors on the resource configuration efficiency is mainly explored based on the three dimensions of economy, industry, and society. In addition, when selecting input-output indicators, the analysis of various controllable influencing factors on the resource configuration efficiency of geriatric care services is carried out from different perspectives in order to comprehensively understand various factors. The Tobit model is further employed to analyze the interfering factors of resource configuration efficiency of the elderly care services. Based on the existing studies and the actual situation about resource configuration of the elderly care services in Shanghai, the specific factors influencing efficiency are selected and exhibited in Table 4.

Therefore, regression analysis is performed in this study with the technical efficiency of resource configuration of the elderly care services in Shanghai from 2010 to 2019 as the dependent variable and five indexes as the explanatory variables of the Tobit model. The five indexes include Shanghai GDP (100 million RMB) from 2010 to 2019, institutions engaged in the elderly care (number), day service institutions in the community (number), medical service institutions engaged in the elderly care (number), and the density of the elderly Population. As stated, the statistics are collected from the Shanghai Statistical Yearbook and Shanghai Municipality's Elderly Population and Elderly Career Monitoring Statistics from 2010 to 2019, as well as the analysis previously performed in the paper. Relevant descriptive statistics of the data are offered in Table 5.

4.3. Hypothesis and Research Questions. Based on the studies carried out by other scholars, the factors influencing resource configuration efficiency of elderly care services in Shanghai are explored from the aspects of the economic 
TABLE 4: Factors influencing efficiency.

\begin{tabular}{|c|c|c|c|c|c|}
\hline \multirow{6}{*}{$\begin{array}{l}\text { Factors and indicators } \\
\text { influencing efficiency }\end{array}$} & $\begin{array}{l}\text { Analysis } \\
\text { dimension }\end{array}$ & Index & Unit & Description & Signs \\
\hline & Economic level & GDP of Shanghai & RMB100 million & $\begin{array}{c}\text { Regional economic development } \\
\text { level }\end{array}$ & $Y_{1}$ \\
\hline & & $\begin{array}{l}\text { Institutions engaged in the } \\
\text { elderly care }\end{array}$ & Number & & $Y_{2}$ \\
\hline & Industrial level & $\begin{array}{l}\text { Day service institutions in the } \\
\text { community }\end{array}$ & Number & $\begin{array}{l}\text { Development level of the elderly } \\
\text { care industry }\end{array}$ & $Y_{3}$ \\
\hline & & $\begin{array}{l}\text { Medical service institutions } \\
\text { engaged in the elderly care }\end{array}$ & Number & & $Y_{4}$ \\
\hline & $\begin{array}{c}\text { Social } \\
\text { environment }\end{array}$ & $\begin{array}{l}\text { Population density of the } \\
\text { elderly }\end{array}$ & $\begin{array}{l}\text { Persons/square } \\
\text { kilometers }\end{array}$ & $\begin{array}{l}\text { Objective environment of } \\
\text { elderly care service resources }\end{array}$ & $Y_{5}$ \\
\hline
\end{tabular}

TABLE 5: Descriptive statistics of factors influencing resource allocation efficiency of the Shanghai pension service in $2010-2019$.

\begin{tabular}{|c|c|c|c|c|}
\hline Name of variable & Average value & Standard deviation & Minimum value & Maximum value \\
\hline Technical efficiency value & 0.86 & 0.95 & 0.757 & 1.00 \\
\hline GDP of Shanghai & 27157.07 & 6912.82 & 17915.41 & 38155.32 \\
\hline Number of institutions engaged in the elderly care & 671.90 & 39.73 & 625 & 724 \\
\hline Day service institutions in the community & 451.40 & 147.42 & 303 & 720 \\
\hline Medical service institutions engaged in the elderly care & 30.4 & 11.46 & 18 & 55 \\
\hline Density of the senior population & 669.73 & 103.92 & 522.07 & 817.16 \\
\hline
\end{tabular}

level, industrial level, and social environment level. The analysis starts from the element framework of comprehensive and systematic influencing factors.

Hypothesis 1. There is a positive correlation between Shanghai GDP and the technical efficiency of the resource configuration of elderly care services.

From an economic point of view, regional economic development level with the GDP of Shanghai as the representative is the fundamental influencing on the resource configuration efficiency of elderly care services. The economy serves as the root of social development. The higher the GDP, the better the economic development in this area and the higher the level of economic development. The rapid development of society at all levels promotes the high resource configuration efficiency of elderly care services to some extent.

Hypothesis 2. There is a positive correlation between the level of industry development and the technical efficiency of resource configuration of elderly care services.

At the industry level, the level of sophistication of geriatric care facilities, community day care, and elderly medical service facilities could affect the efficiency of the resource configuration of geriatric care services in an area. The higher the level of development in an area, the richer the industry experience and experience. It makes a positive contribution to the resource configuration of geriatric care services.

Hypothesis 3. There is a positive correlation between the density of the elderly population and the technical efficiency of the resource configuration of elderly care services.

At the level of social environment, the density of the elderly population denotes the reflection of the elderly population per unit land area. It can effectively measure the degree of accessibility to the resource of elderly care services. We believe that there is a positive correlation between the elderly population density and the population obtaining the resource of elderly care services. The higher the population density of the elderly, the greater their access to resources for care for the elderly. To some extent, the cost of administration and monitoring per unit area will decrease, resulting in an increase in the economies of scale and efficiency of the resource configuration of geriatric care services.

According to the three hypotheses, the multiple regression model is established in this study with the technical efficiency as the dependent variable and the five previously discussed indices as explanatory variables.

$$
Y=\beta_{0}+\beta_{a} P_{1}+\beta_{b} P_{2}+\beta_{c} P_{3}+\beta_{d} P_{4}+\beta_{e} P_{5}+\varepsilon,
$$

where Y refers to the value of resource configuration efficiency of elderly care services in Shanghai; $\beta_{0}$ denotes the constant term; $\beta_{a}, \beta_{b}, \beta_{c}, \beta_{d}$, and $\beta_{e}$ represent the GDP, institutions engaged in the elderly care, day service institutions in the community, medical service institutions engaged in the elderly care, and the density of the elderly population, respectively; and $\varepsilon$ indicates the random disturbance term.

4.4. Regression Results and Analysis. The factors influencing the resource configuration efficiency of elderly care services are measured using the Stata 15.0 software. The regression results are obtained, as shown in Table 6.

\section{Discussion}

Findings of this study shed some light on the current efficiency evaluation of the resource configuration and the future development for both practitioners and policy makers. It is also noted that, when establishing the 
TABLE 6: Analysis of factors influencing the efficiency of pension resources allocation.

\begin{tabular}{lccccc}
\hline Dimensions & $\begin{array}{c}\text { Economic } \\
\text { level }\end{array}$ & Industrial level & & $\begin{array}{c}\text { Social environment } \\
\text { level }\end{array}$ \\
\hline Indicators & $\begin{array}{l}\text { GDP of } \\
\text { Shanghai }\end{array}$ & $\begin{array}{c}\text { Institutions engaged in } \\
\text { the elderly care }\end{array}$ & $\begin{array}{c}\text { Day service institutions } \\
\text { in the community }\end{array}$ & $\begin{array}{c}\text { Medical service institutions } \\
\text { engaged in the elderly care }\end{array}$ & $\begin{array}{c}\text { Density of the senior } \\
\text { population }\end{array}$ \\
efficiency & $\begin{array}{c}0.000804 \\
(2.04)\end{array}$ & $0.0031597^{* *}(3.85)$ & $0.0030568^{* *}(3.66)$ & $0.0006829^{* *}(0.66)$ & $0.0013795^{*}(0.81)$ \\
\hline
\end{tabular}

Note. The value of $t$ is in parentheses; “*”, “**”, and “***” indicate the significance levels at $10 \%, 5 \%$, and $1 \%$, respectively.

evaluation indexes, the policy environment and other related indicators were not included due to the complexity and data accessibility, and accordingly the study was unable to reflect the overall picture of the resource allocation efficiency issue. Also, in future research, the nature of the various resources available for elderly care services can be further subdivided, and the factors that affect the efficiency of different types of resources can be examined separately.

5.1. Conclusions. The overall resource configuration efficiency of elderly care service in Shanghai is not high. The technique efficiency about the resource configuration efficiency of elderly care service in Shanghai "first increases and then decreases". Among all the ten years' studies, valid DEA was only realized in 2014, accounting for $10 \%$ of the total. Then, it shows a decreasing trend. However, from the point of view of purely technical efficiency, the average value obtained from pure technical efficiency of the resource configuration of elderly care service reached 0.990, suggesting that the system and management of resource configuration are at a high level. At the current technical level, the resource can be input to promote its effective utilization.

Scale efficiency is the key factor influencing the technical efficiency of the resource configuration of elderly care services in Shanghai. The average value of the resource configuration efficiency of elderly care service in Shanghai from 2010 to 2019 was 0.888 , which is slightly above 0.872 (the average value of technical efficiency). Over the 10-year study, pure technical efficiency was achieved in the first six years, accounting for $70 \%$ of the total. Moreover, the average value obtained from pure technical efficiency was as high as 0.990 , approaching 1 . The technical efficiency of the resource configuration of the geriatric care services in Shanghai is therefore heavily influenced by the economies of scale.

Complexity and diversity are reflected in the influencing factors of resource configuration efficiency of elderly care services in Shanghai. Regarding the regression analysis on the influencing factors of resource configuration efficiency of elderly care services in Shanghai, there is a positive correlation between resource configuration efficiency of elderly care services and the four indexes (the institutions engaged in the elderly care, day service institutions in the community, medical service institutions engaged in the elderly care, and the density of the elderly population). To sum up, the factors influencing resource configuration efficiency of elderly care services are diverse. Hence, the evaluation is supposed to start from the multidimensional perspective and comprehensively consider various influencing factors such as technical efficiency and resource utilization. Specifically, objective and comprehensive results can be obtained to explore the effective path for improving the resource configuration efficiency of elderly care services.

5.2. Management Implies. In the view of the empirical analysis on the status quo, efficiency evaluation, and influencing factors related to resource configuration of elderly care services in Shanghai, corresponding countermeasures are proposed from the three dimensions of the elderly group, the elderly care industry, and market environment. In this way, the study may improve resource configuration efficiency of elderly care services in Shanghai and enable the industry to develop efficiently.

First, value the willingness of the elderly in old age to engage in social activities. From the viewpoint of long-term development, the resource of elderly care services offered by the government uniformly is limited to some extent. Hence, it should be first supplied to the elderly who are in great demand of such safeguard to maximize the marginal utility, instead of providing all the elderly with basically the same elderly care services under the lowest conditions. Thus, the social role of the healthy seniors of low ages is transformed from a single consumer to producer. They would conduct production and consumption concurrently and are transformed to the positive creators of the resource relevant to elderly care services rather than the passive recipients of the resource [24].

Second, guide the elderly care industry to improve itself reasonably. The capital employed is to be increased; the flow of capital should be appropriately directed; and the subsidy received on the basis of the policy should be distributed appropriately. In addition, although government spending in various areas of the elderly care industry has grown rapidly, the resource should be used wisely. Simultaneously, the capital supervision should be strengthened, accompanied by improved corresponding regulatory institutions and systems [25].

Third, the efficiency of resource configuration in the geriatric care industry needs to be emphasized to realize the optimal resource configuration. Moreover, the elderly care sector in different regions should be developed by adapting the measures to local conditions and taking full account of the economic level, social development characteristics, and the objective environment of the specific areas. It should be combined with an appropriate map of the geographic location where the elderly care facilities are located. 
Fourth, the promotion of consumption in the elderly care market. Market demand serves as the key factor pulling resource configuration. The market requirement in the elderly care market should be further subdivided to improve the resource configuration level of elderly care services. The government must take the initiative to overcome the negative obstacles affecting social capital participation in elderly care in order to continually attract social capital to the elderly care sector.

Finally, the key role of the market in shaping the market resource should be exerted. It points to a more important responsibility of the government than to the deprivation of government responsibility [26]. This is because elderly care services are within the range of activities falling in the scope of governmental public function, which is a distinctive feature.

\section{Data Availability}

The data used to support the findings of this study are included within the article.

\section{Conflicts of Interest}

The authors declare that there are no conflicts of interest regarding the publication of this paper.

\section{References}

[1] H. Li, C. Duan, and M.-D. Chunyu, "A study of the factors influencing the residential preferences of the elderly in China," Sustainability, vol. 13, no. 10, pp. 1-20, 2021.

[2] Q. Feng, W.-J. J. Yeung, Z. Wang, and Y. Zeng, "Age of retirement and human capital in an aging China, 2015-2050," European Journal of Population, vol. 35, no. 1, pp. 29-62, 2019.

[3] S. J. McLaughlin, Y. Chen, S. S. X. Tham, J. Zhang, and L. W. Li, "Healthy aging in China: benchmarks and sociostructural correlates," Research on Aging, vol. 42, no. 1, pp. 23-33, 2020.

[4] B. Lars-Erik and M. Haraldsvik, "Efficiency potential and determinants of efficiency: an analysis of the care for the elderly sector in Norway," International Tax and Public Finance, vol. 16, no. 4, pp. 468-486, 2009.

[5] J. Laine, M. Linna, U. Häkkinen, and A. Noro, "Measuring the productive efficiency and clinical quality of institutional longterm care for the elderly," Health Economics, vol. 14, no. 3, pp. 245-256, 2005.

[6] J. O. Bock, H. Matschinger, H. Brenner et al., "Inequalities in out-of-pocket payments for health care services among elderly Germans-results of a population-based cross-sectional study," International Journal for Equity in Health, vol. 13, no. 1, pp. 1-13, 2014.

[7] H. Stoddart, E. Whitley, I. Harvey, and D. Sharp, "What determines the use of home care services by elderly people?" Health and Social Care in the Community, vol. 10, no. 5, pp. 348-360, 2002.

[8] G. Garavaglia, E. Lettieri, T. Agasisti, and S. Lopez, "Efficiency and quality of care in nursing homes: an Italian case study," Health Care Management Science, vol. 14, no. 1, pp. 22-35, 2011.

[9] C.-Yi Wu, H.-Y. Hu, N. Huang, Y.-T. Fang, Y.-J. Chou, and C.-P. Li, "Determinants of long-term care services among the elderly: a population-based study in Taiwan," PLoS One, vol. 9, no. 2, pp. 1-10, 2014.

[10] J. L. Iparraguirre and R. Ma, "Efficiency in the provision of social care for older people. A three-stage data envelopment analysis using self-reported quality of life," Socio-Economic Planning Sciences, vol. 49, pp. 33-46, 2015.

[11] Q. Shao, J. Yuan, J. Lin, W. Huang, J. Ma, and H. Ding, "A SBM-DEA based performance evaluation and optimization for social organizations participating in community and home-based elderly care services," PLoS One, vol. 16, no. 3, Article ID e0248474, 2021.

[12] J. McDonald, "Using least squares and Tobit in second stage DEA efficiency analyses," European Journal of Operational Research, vol. 197, no. 2, pp. 792-798, 2009.

[13] A. Hoff, "Second stage DEA: comparison of approaches for modelling the DEA score," European Journal of Operational Research, vol. 181, no. 1, pp. 425-435, 2007.

[14] A. Khosravi, M. Fallah, and S. E. Najafi, "An EFQM-fuzzy network data envelopment analysis model for efficiency assessment in organizations," Journal of Mathematics, vol. 2021, pp. 1-17, Article ID 6655857, 2021.

[15] P. Li and J.-S. Zhang, "A new hybrid method for China's energy supply security forecasting based on ARIMA and XGBoost," Energies, vol. 11, no. 7, pp. 1-28, 2018.

[16] Q. Diao and Y. Liu, "Fuzzy set qualitative comparative analysis (FSQCA) applied to the driving mechanism of total factor productivity growth," Journal of Mathematics, vol. 2021, Article ID 8182454, 8 pages, 2021.

[17] Ü. Sağlam, “A two-stage data envelopment analysis model for efficiency assessments of 39 state's Wind power in the United States," Energy Conversion and Management, vol. 146, no. 146, pp. 52-67, 2017.

[18] R. Jing, T. Xu, X. Lai, E. Mahmoudi, and H. Fang, "Technical efficiency of public and private hospitals in Beijing, China: a comparative study," International Journal of Environmental Research and Public Health, vol. 17, no. 1, p. 82, 2019.

[19] A. Charnes, W. W. Cooper, and E. Rhodes, "Measuring the efficiency of decision making units," European Journal of Operational Research, vol. 2, no. 6, pp. 429-444, 1978.

[20] R. D. Banker, A. Charnes, and W. W. Cooper, "Some models for estimating technical and scale inefficiencies in data envelopment analysis," Management Science, vol. 30, no. 9, pp. 1078-1092, 1984.

[21] W. W. Cooper, L. M. Seiford, and J. Zhu, Handbook on Data Envelopment Analysis, Springer, Berlin, Germany, 2011.

[22] J. Tobin, "Estimation of relationships for limited dependent variables," Econometrica, vol. 26, no. 1, p. 24, 1958.

[23] B. X. Tran, M. T. Hoang, H. Q. Pham et al., "The operational readiness capacities of the grassroots health system in responses to epidemics: implications for COVID-19 control in Vietnam," Journal of Global Health, vol. 10, no. 1, p. 11006, 2020.

[24] S. Li and S. Lin, "Population aging and China's social security reforms," Journal of Policy Modeling, vol. 38, no. 1, pp. 65-95, 2016.

[25] B. Lu, H. Mi, Y. Zhu, and J. Piggott, “A sustainable long-term health care system for aging China: a case study of regional practice," Health Systems \& Reform, vol. 3, no. 3, pp. 182-190, 2017.

[26] Y. Cheng, S. Gao, S. Li, Y. Zhang, and M. Rosenberg, "Understanding the spatial disparities and vulnerability of population aging in China," Asia \& the Pacific Policy Studies, vol. 6, no. 1, pp. 73-89, 2019. 